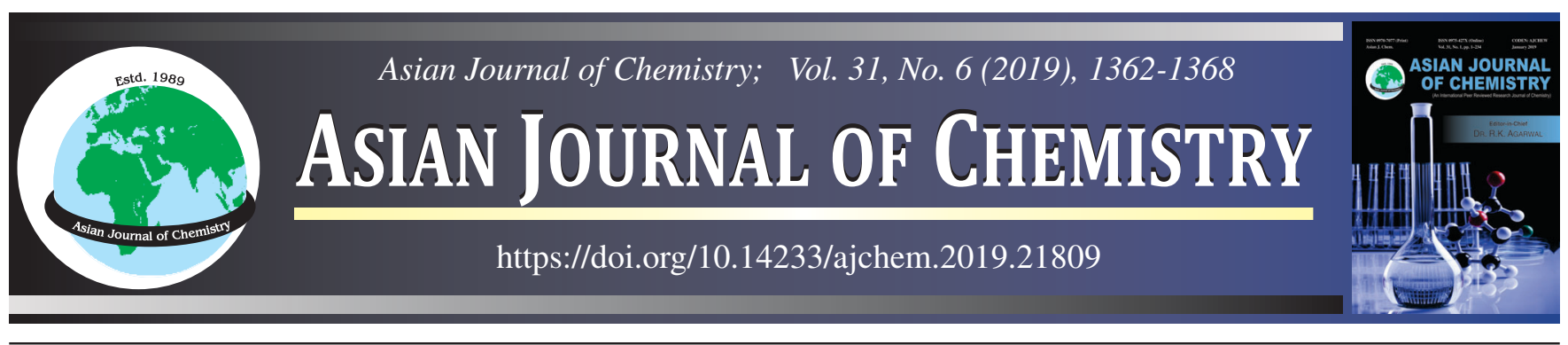

\title{
A Hydrothermal Synthesis of Graphene Quantum Dots Modified Carbon Paste Electrode as an Efficient Electro Sensor Towards L-Ascorbic Acid
}

\section{SATHEesh Durairaj ${ }^{1,2}$ and Ravichandran Kulandaivelu ${ }^{1, *}$}

${ }^{1}$ Department of Analytical Chemistry, University of Madras, Chennai-600025, India

${ }^{2}$ Department of Chemistry, Siddha Central Research Institute, Chennai-600106, India

*Corresponding author: E-mail: raavees@gmail.com; adsatheesh@gmail.com

Received: 12 November 2018;

Accepted: 12 March 2019;

Published online: 29 April 2019;

AJC-19381

The tremendous electronic assets of graphene, with its charge carriers parroting relativistic graphene quantum dots and its potential in numerous applications, have ensured a hasty evolution of interest in this ground-breaking material. The graphene quantum dots, in the size range of 1-5 nm, showed $0 \mathrm{D}$ morphology, which exists with few atomic layers of wideness and have zigzag edge structure. Herein, We report on electrochemical behaviour of graphene quantum dots modified electrode that hold edges and basal plane content, accelerated the anodic peak current with a sensitivity of about $0.68 \mathrm{~mA} \mathrm{mM}^{-1}$ and offers 1.4 times higher sensitivity towards the oxidation of ascorbic acid.

Keywords: Graphene, Nanoparticles, Ascorbic acid, Oxidation, Sensors.

\section{INTRODUCTION}

Graphene has generated enormous excitement owing to its exceptional properties viz., large theoretical surface area of over $2600 \mathrm{~m}^{2} \mathrm{~g}^{-1}$, high mechanical flexibility, excellent electrocatalytic activity, outstanding chemical and thermal stability, etc. These properties make it as an interesting candidate for whole range of newer applications [1-4]. Graphene composite materials exhibits high electrical conductivity and possess potential applications in biosensing due to its high electron mobility and very low resistance. Graphene quantum dots also have the potential to replace the electron conducting materials $[2,5]$. Thus the graphene used in electrochemistry are produced by reduction of graphene oxide. Graphene from graphene oxide reduction, which is called chemically reduced graphene oxide, usually has structural defects and functional groups [6], which are profitable for electrochemical applications [7]. For highly sensitive electrochemical device, utility of graphene was promoted through higher proportion of edge plane sites and basal plane surface for assisting electron transfer kinetics. This prospective approach is achieved by converting the $1 \mathrm{D}$ graphene sheets into $0 \mathrm{D}$ graphene quantum dots (GQDs) [8,9].

Graphene quantum dots are nano meter sized fragments of graphene, wherein excitations are confined in all three spatial dimensions and possess unique properties owing to the quantum confinement and edge effects [10,11]. These promising materials should be used for determination of biological samples with modified electrode effectively, due to the peculiar properties of GQDs [12]. Graphene quantum dots are chemically inert, biocompatible and non-toxic. These GQDs possess high surface area, large diameter and better surface grafting using $\pi-\pi$ conjugation and surface groups. Therefore, researches are carried out on GQDs in aspects of chemistry, physical, materials, biology and interdisciplinary science [9] as their diameters are mainly distributed in a larger range (3-10 $\mathrm{nm}$ ).

Most biological importance of ascorbic acid, which is an antioxidant acting a substantial role in protecting living cells against oxidative injury in biological metabolism and it has been used for the treatment of various medical disorders [13]. The direct oxidation of ascorbic acid at bare electrode requires over potential which results in electrode fouling by its oxidation products. In such a situation, the reproducibility, selectivity and sensitivity of the electrodes get affected [14].

Ascorbic acid, as an antioxidant plays a substantial role in protecting living cells against oxidative injury in biological metabolism and it has been used for the treatment of various medical disorders. The direct oxidation of ascorbic acid at bare electrode requires high over potential, which results in elec-

This is an open access journal, and articles are distributed under the terms of the Creative Commons Attribution-NonCommercial-ShareAlike 4.0 (CC BY-NC-SA 4.0) International License which allows readers to freely read, download, copy, distribute, print, search, or link to the full texts of its articles and to use them for any other lawful non-commercial purpose as long as the original source is duly acknowledged. 
trode fouling by its oxidation products with poor reproducibility, low selectivity and low sensitivity. Earlier, various chemically modified electrodes like PANI, PPy and PEDOT have been attempted to determine ascorbic acid [15].

\section{EXPERIMENTAL}

Synthesis of graphene quantum dots (GQDs): High purity graphite powder, all solvents and reagents were used without further purification, purchased from Sigma Aldrich. Graphene oxide was synthesized by Hummers method. In a typical experiment, a flask containing $\mathrm{H}_{2} \mathrm{SO}_{4}$ was placed in an ice bath, followed by the addition of $3 \mathrm{~g}$ of $\mathrm{NaNO}_{3}$ and $5 \mathrm{~g}$ of graphite. Mixing of sulphuric acid is done in the ratio of $50 \mathrm{~mL}$ per gram of graphite. The complete reaction is maintained at $5^{\circ} \mathrm{C}$ and the mixture was stirred for $0.5 \mathrm{~h}$. Then $35 \mathrm{~g}$ of $\mathrm{KMnO}_{4}$ was slowly added into the mixture, because of its possibility to exothermic explosions. Precautions were taken, while carrying out this reaction $[16,17]$.

After $0.5 \mathrm{~h}$ of mechanical stirring below $5^{\circ} \mathrm{C}$, the temperature was raised to $80^{\circ} \mathrm{C}$ and maintained for $1 \mathrm{~h} .300 \mathrm{~mL}$ of deionized water was added dropwise into the mixture with stirring and the temperature was controlled below $98^{\circ} \mathrm{C}$ via a water bath. The viscous mud was diluted by $1000 \mathrm{~mL}$ of deionized water. A certain amount of (approx. $20 \%$ ) hydrogen peroxide was dripped into the diluted mud $\left(\mathrm{MnO}_{2}\right)$ to reduce the unreacted $\mathrm{KMnO}_{4}$. The above mixture was washed a number of times with diluted acidic medium (dil. $\mathrm{HCl}$ ), then washed with deionized water until the $\mathrm{pH}$ of supernatant became neutral and filtered through a $0.22 \mu \mathrm{m}$ micro porous membrane to remove the acids and large size particles [17].

Above obtained graphene oxide $(0.5 \mathrm{~g})$ was re-dispersed in deionized water $(50 \mathrm{~mL})$. Subsequently it was transferred to a Teflon-lined autoclave and heated at $180^{\circ} \mathrm{C}$ for $15 \mathrm{~h}$. Then cooling to room temperature, the resulting black suspension was again filtered through a $0.22 \mu \mathrm{m}$ micro porous membrane and a filter solution was separated. Finally, the resulting solution was dried at $60{ }^{\circ} \mathrm{C}$ under vacuum for $24 \mathrm{~h}$ where black solid GQDs was obtained [18].

Preparation of modified electrodes: The modified carbon paste electrode (CPE) was fabricated by combining $0.005 \mathrm{~g}$ of GQDs, $0.5 \mathrm{~g}$ of graphite powder and paraffin wax. The GQDs was dispersed in ethanol using an ultrasonic bath followed by addition of graphite powder and paraffin wax to the mixture. A CPE was prepared by mixing graphite powder with gently heated paraffin wax and packing the resultant paste into a syringe ( $2 \mathrm{~mm}$ diameter and $1 \mathrm{~cm}^{3}$ deep). A copper wire was inserted through the centre of the rod to the active material (GQDs and carbon paste ). The voltammogram were obtained for electrochemical oxidation of ascorbic acid using CPE with varying proportions of GQDs. Results shown that $0.005 \mathrm{~g}$ was the optimal amount of GQDs in $0.5 \mathrm{~g}$ of graphite [19].

Characterization: Graphene quantum dots samples in pure solid state were studied and characterized by Laser Raman spectroscopy (Raman-11i, nano photon, Japan) in scattering mode. Structural analysis of GQDs was elucidated by powder $\mathrm{X}$-ray diffraction (XRD) analysis using RigakuMiniFlexII-C system with $\mathrm{CuK}_{\alpha}(\lambda=1.54056 \mathrm{~nm})$ radiation at a scanning rate of $1 \% \mathrm{~min}$. The surface morphology of GQDs was investigated by using high resolution transmission electron microscopy (FEI Technai- T20G2).

\section{RESULTS AND DISCUSSION}

Characterization of GQDs: The Raman spectrum for GQDs revealed the characteristic G band at $1594 \mathrm{~cm}^{-1}$ and D band at $1346 \mathrm{~cm}^{-1}$ with an intensity ratio (ID/IG) of 1.2 [Fig. $1(\mathrm{c})$ ] which is correspond to the $\mathrm{D}$ and $\mathrm{G}$ bands. It was reported that the $\mathrm{G}$ band agrees to the first-order scattering of the $\mathrm{E}_{2 \mathrm{~g}}$ mode from the $s p^{2}$ carbon domains and the D band creates from the disorder-induced mode associated with structural defects and imperfections. Therefore, the intensity ratio of $I_{D} / I_{G}$ is

(b)

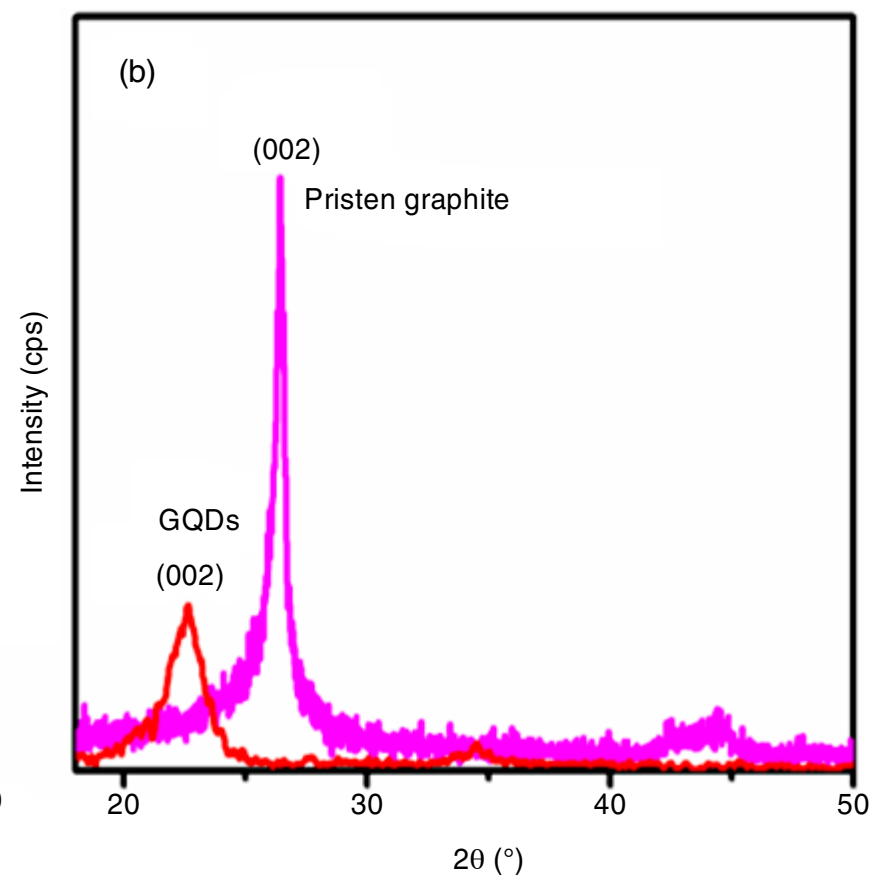

Raman shift $\left(\mathrm{cm}^{-1}\right)$

Fig. 1. (a) Raman spectrum of rGO and GQDs, (b) XRD patterns of the pristine graphite and GQDs 
generally used as a measure to evaluate the quality of the graphitic structures [20-22].

This larger $\mathrm{I}_{\mathrm{D}} / \mathrm{I}_{\mathrm{G}}$ ratio designates the higher defects in the GQDs and partially disordered crystal structure, arising out of smaller $s p^{2}$ cluster size of GQDs, when compared to reduced graphene oxide [9,23] (Table-1).

\section{TABLE-1}

RAMAN SPECTRAL $\mathrm{I}_{\mathrm{D}} / \mathrm{I}_{\mathrm{G}}$ RATIO OF GQDs AND rGO

\begin{tabular}{lcl}
\hline Raman band $\left(\mathrm{cm}^{-1}\right)$ & Sample name & $\mathrm{I}_{\mathrm{D}} / \mathrm{I}_{\mathrm{G}}$ ratio \\
\hline \multirow{2}{*}{$\mathrm{D}=1346, \mathrm{G}=1575$} & $\mathrm{GQDs}$ & 1.2 \\
& $\mathrm{rGO}$ & $0.5[23]$ \\
\hline
\end{tabular}

Graphite exhibited a sharp (002) peak centered at $26.45^{\circ}$ corresponding to the typical $0.334 \mathrm{~nm}$ interlayer spacing and in contrast, a weak broad peak (002) at $22.60^{\circ}$ corresponding to interlayer spacing of $0.296 \mathrm{~nm}$, which is attributed to disordered stacking of some of the GQDs in the XRD pattern [23,24] as shown in Fig. 1(b) (Table-2).

TABLE-2

STRUCTURAL PARAMETERS OF GQDs

\begin{tabular}{ccccc}
\hline $\begin{array}{c}2 \theta \\
\left({ }^{\circ}\right)\end{array}$ & $\begin{array}{c}\text { Plane } \\
(\mathrm{hkl})\end{array}$ & $\begin{array}{c}\text { Inter planer } \\
\text { spacing 'd' }(\mathrm{nm})\end{array}$ & $\begin{array}{c}\text { FWHM } \\
(\mathrm{rad})\end{array}$ & $\begin{array}{c}\text { Average particle } \\
\text { size, D }(\mathrm{nm})\end{array}$ \\
\hline 22.6 & 002 & 0.296 & 1.6722 & 4.85 \\
\hline
\end{tabular}

The HRTEM investigation [Fig. 2(a)] confirmed that the surface morphology of GQDs were spherical and regularly distributed. The average particle size of GQDs was found to be $4.85 \mathrm{~nm}$. The calculated mean particle size of GQDs using HRTEM was $4.95 \mathrm{~nm}$. This value is quite compared with XRD structural data analysis (Table-3).

\begin{tabular}{cc}
\multicolumn{2}{c}{ TABLE-3 } \\
\multicolumn{2}{c}{ PARTICLE SIZE OF GQDs OBTAINED } \\
WITH HRTEM AND XRD METHODS \\
\hline Methods & Particle size $(\mathrm{nm})$ \\
\hline HRTEM & 4.95 (Mean) \\
XRD & 4.86 \\
\hline
\end{tabular}

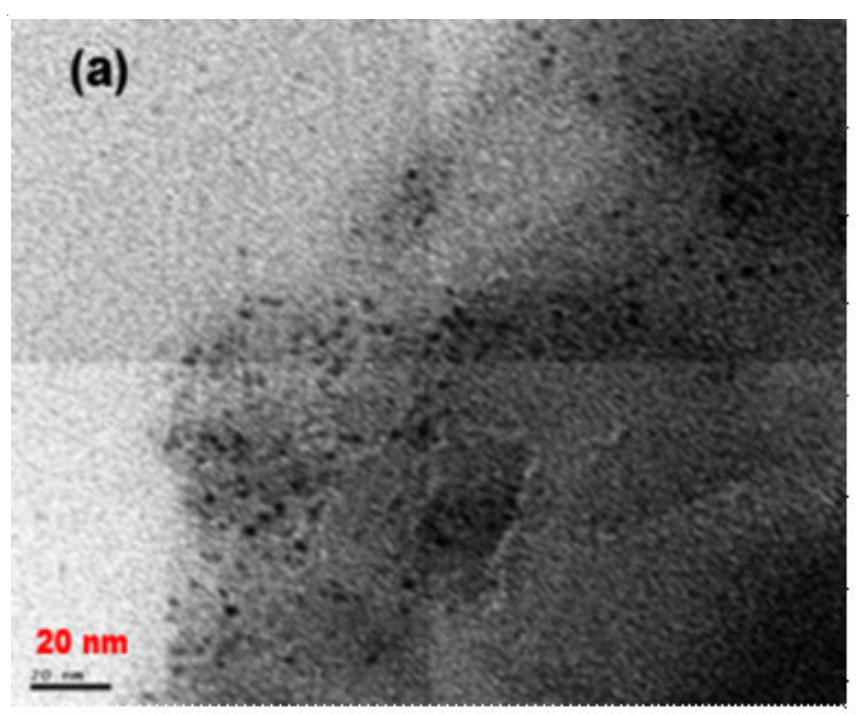

The FT-IR spectrum of GQDs [9] (Fig. 3) shown the change in strongest vibrational absorption band of $\mathrm{C}=\mathrm{O} / \mathrm{COOH}$ at $1720 \mathrm{~cm}^{-1}$ usually observed for graphene oxide to very weak band. The conjugated diene $-\mathrm{C}=\mathrm{C}$ - of basal plane peak appeared at $1588 \mathrm{~cm}^{-1}$. The carbonyl group of ketone $(\mathrm{C}=\mathrm{O})$ produced a weak stretching peaks at 1496 and $1425 \mathrm{~cm}^{-1}$. The carboxylic acid -C-O band appeared at $1130 \mathrm{~cm}^{-1}$. The out plane bending and stretching peaks of -OH group in carboxylic acid was observed at 925 and $3275 \mathrm{~cm}^{-1}$.

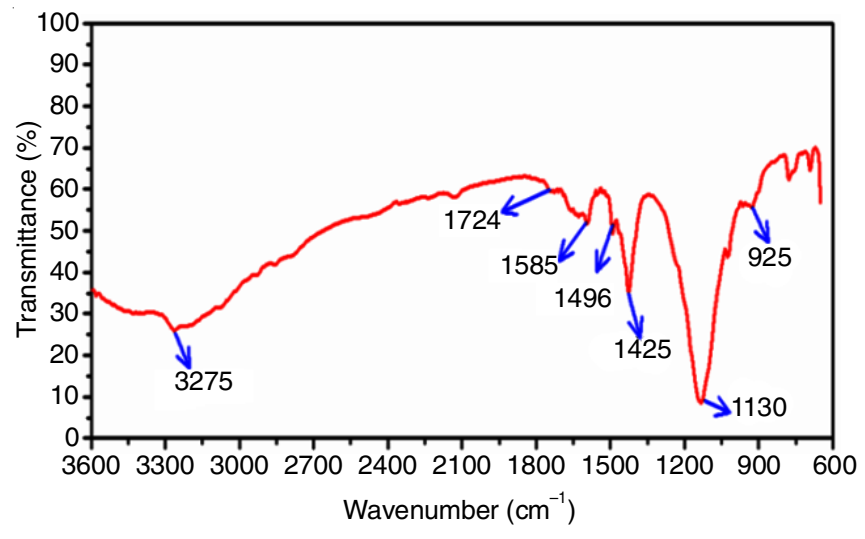

Fig. 3. FT-IR spectrum of GQDs

X-ray photoelectron spectroscopy: Fig. 4 shows the XPS spectra of graphene oxide and hydrothermally reduced graphene quantum dots. Fig. 4(a)\&(b) shows XPS survey spectrum designate direct evidence of the formation of graphene oxide and the reduction of graphene oxide to GQDS by hydrothermally. The XPS data matches well with the data reported [4]. Fig. 4(c)\&(d) shows a decrease in the number of carbonyl groups and an increase in the number of carbon double bonds were found in graphene quantum dots. $\mathrm{C}$ 1s spectra of graphene oxide, can be broken into four components (i) non-oxygenated ring $\mathrm{C}(284.5 \mathrm{eV})$, (ii) the $\mathrm{C}$ in the $\mathrm{C}-\mathrm{O}$ bonds $(285.3 \mathrm{eV})$, (iii) the carbonyl $\mathrm{C}(\mathrm{C}=\mathrm{O}, 287.1 \mathrm{eV})$ and (iv) the carboxylate carbon $(\mathrm{O}-\mathrm{C}=\mathrm{O}, 289.0 \mathrm{eV}) . \mathrm{C} 1 \mathrm{~s}$ spectra of graphene quantum dots also exhibited similar functional groups to those of

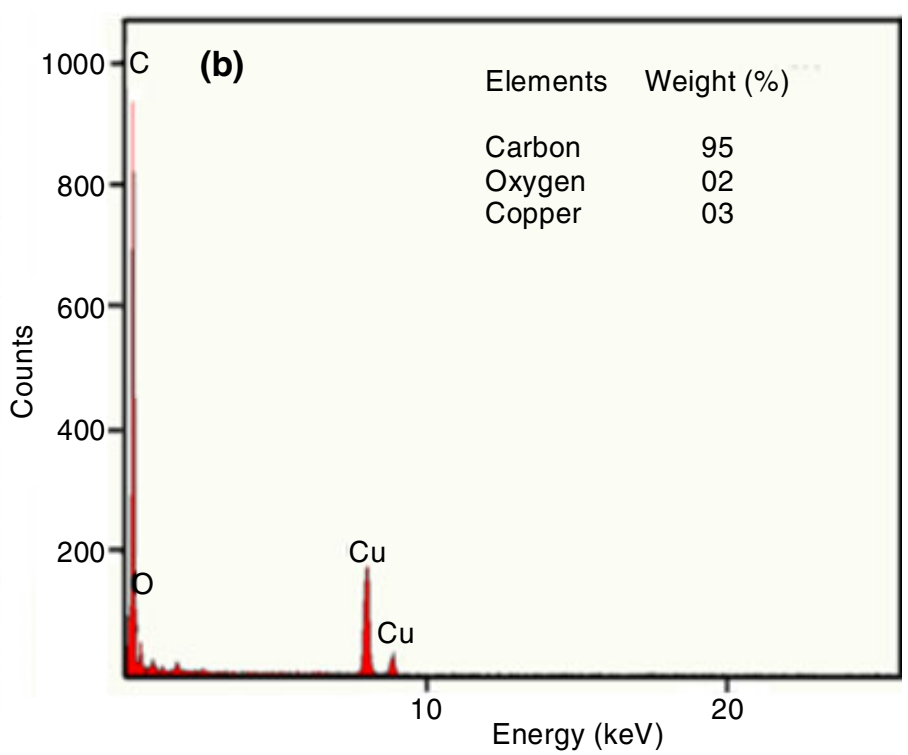

Fig. 2. TEM images of GQDs sheets $20 \mathrm{~nm}$ magnification. (b) EDX spectrum of GQDs 

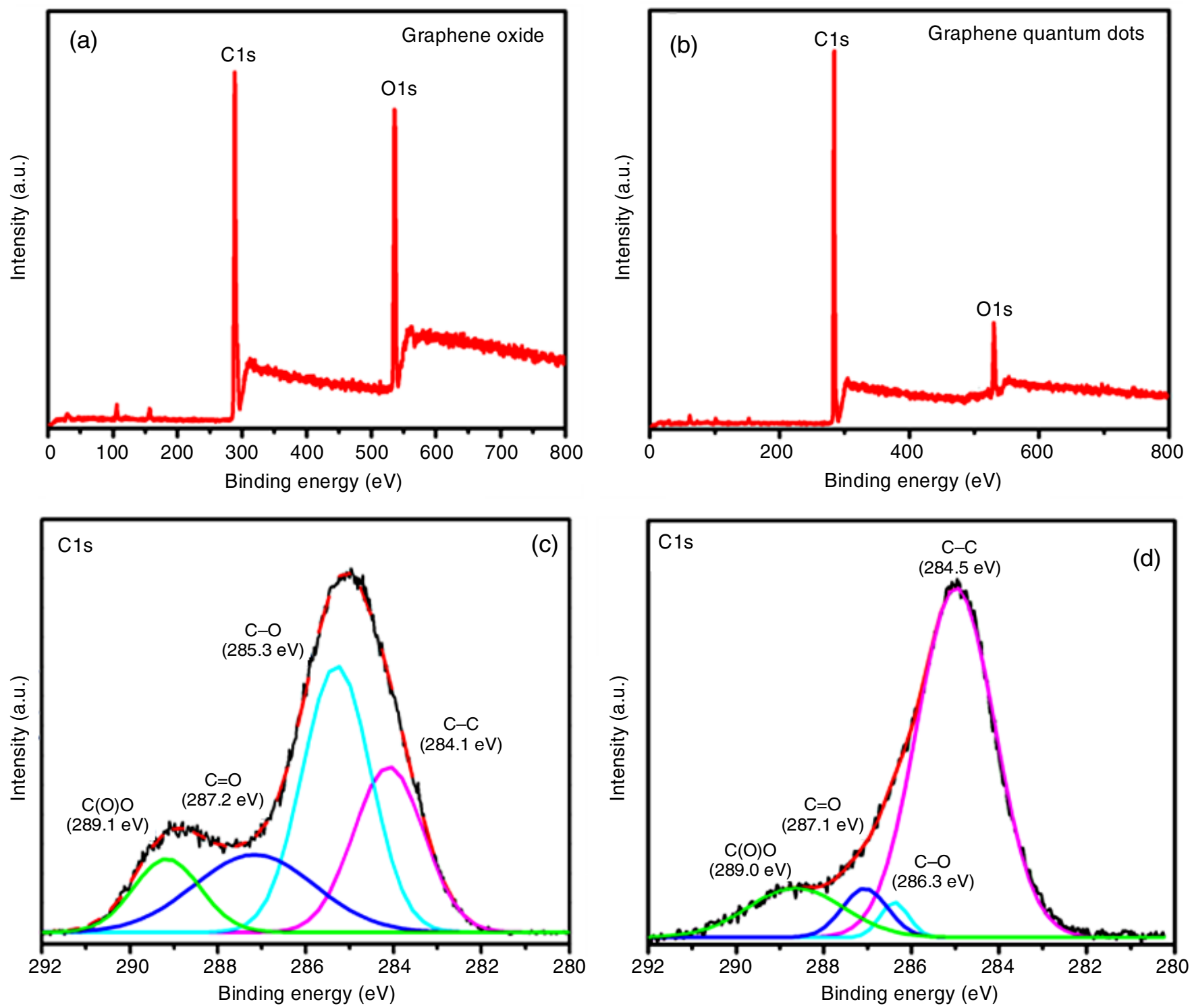

Fig. 4. (a) General XPS of graphene oxide (b) General XPS of GQDs (c) XPS C1s spectrum of graphene oxide (d) XPS C1s spectrum of GQDs

graphene oxide. The peak intensities of these components for the reduced GQDs sample are much lower than for graphene oxide.

Electrochemical performance of GQDs/CPE modified electrode: Cyclic voltammogram obtained in phosphate buffer solution ( $\mathrm{pH}=8.0$ ) for bare CPE in the absence of analyte (a), both bare CPE (b) and GQDs modified CPE(c) with $2 \mathrm{mM}$ ascorbic acid at a scan rate of $50 \mathrm{mV} \mathrm{S}^{-1}$ were illustrated in Fig. 5.

The oxidation peak current appeared at $+0.31 \mathrm{~V}$ for ascorbic acid (AA) on GQDs/CPE modified electrode, which is 1.4 times greater than that of pure CPE.

The manifestation of carbene-like triplet in ground state produced in basal plane of GQDs at $\mathrm{pH}=8$ influences the oxidation of ascorbic acid at higher current sensitivity than the unmodified electrode.

Fig. 6(a) shows the amperometry responses of GQDs/CPE modified electrode for ascorbic acid detection at an applied potential of $+0.31 \mathrm{~V}$. A subsequent addition of ascorbic acid with stirring in PBS solution resulted a remarkable increase

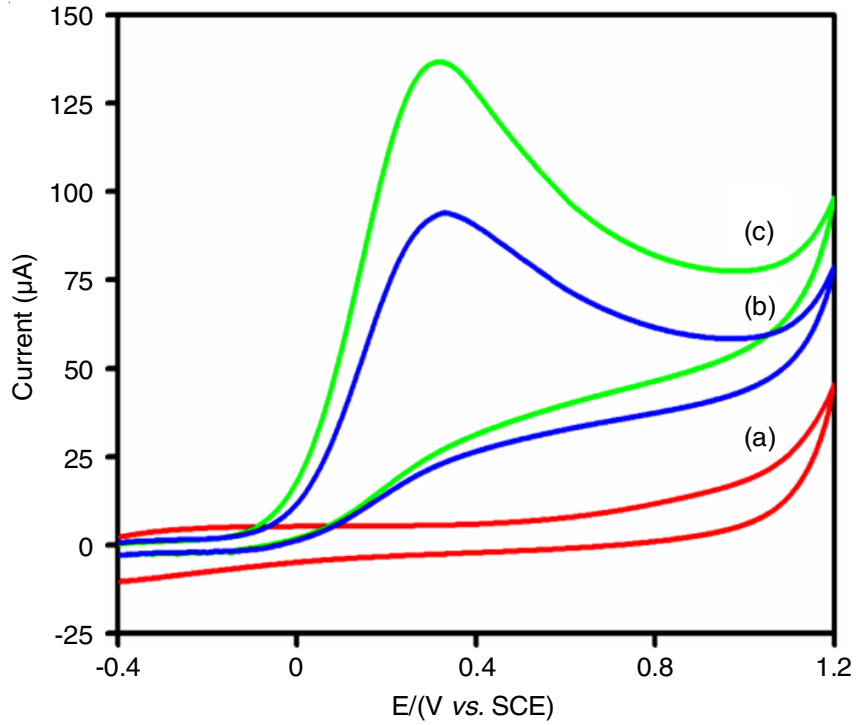

Fig. 5. Cyclic voltammograms of bare CPE absence of analyte (a), unmodified CPE (b) and GQDs modified carbon paste electrode (c) in $2 \mathrm{mM}$ ascorbic acid at a scan rate of $50 \mathrm{mV} \mathrm{S}^{-1}$ 

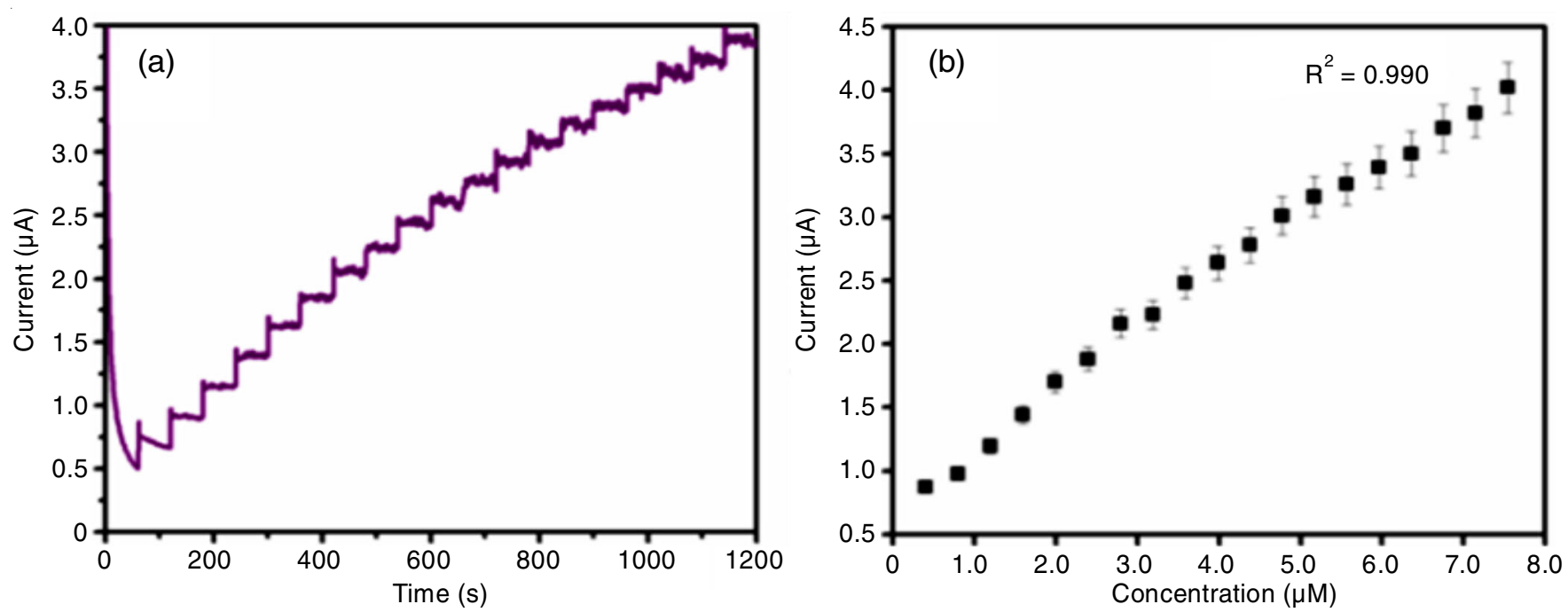

Fig. 6. (a) Amperometric response of the GQDs/CPE modified electrode for the successive additions of ascorbic acid in a stirred $0.1 \mathrm{M}$ PBS ( $\mathrm{pH}$ 8.0) (b) Calibration curve of ascorbic acid concentration of the modified electrode

of oxidation current of ascorbic acid, which reveals the presence of GQDs on the CPE as well as improved it's the catalytic activity of the modified electrode.

Fig. 6(b) shows the calibration plot of the electrocatalytic currents with a linear increase in current of the GQDs/CPE modified electrode with increase in ascorbic acid concentrations. The electrochemical response of the modified electrode showed a linear range from $4.0 \times 10^{-6}$ to $7.5 \times 10^{-5} \mathrm{mM}$ with a correlation coefficient of 0.99 . The sensitivity of the GQDs/ CPE modified electrode was $0.68 \mathrm{~mA} \mathrm{mM}^{-1}$.

Such desirable performance reveals that the GQDs/CPE modified electrode is suitable for electrochemical oxidation of ascorbic acid.

Selectivity of GQDs/CPE modified: Selectivity is one of the very important characteristics for high performance ascorbic acid determination.

In order to understand the factors that can affect the analytical estimation of ascorbic acid by the GQDs/CPE modified electrode, we have studied the effect of potential interferents such as gallic acid (GA), citric acid (CA), ellagic acid (EA) which are the main interfering species in the direct electrochemical oxidation of ascorbic acid.

Fig. 7 shows the typical amperometric responses of citric acid, ellagic acid and gallic acid at $0.31 \mathrm{~V}$ in a $0.1 \mathrm{M}$ PBS solution with stirring. According to the results presented in Fig. 7, adding $1 \mathrm{mM}$ citric acid, ellagic acid and gallic acid only induced a current change compared to the oxidation current from $0.05 \mathrm{mM}$ ascorbic acid. The results revealed that adding $1 \mathrm{mM}$ of these compounds produced a current change equal to the oxidation current availed from $0.5 \mathrm{mM}$ ascorbic acid. Hence, the citric acid, ellagic acid and gallic acid cannot interfere during the oxidation of ascorbic acid at $+0.31 \mathrm{~V}$.

A mechanistic pathway (Scheme-I) is suggested to elucidate the well oxidative response of GQDs modified surfaces of CPE for ascorbic acid.

\section{Conclusion}

In this work, the fabrication of modified electrode by electrochemically synthesized GQDs. An electroanalytical

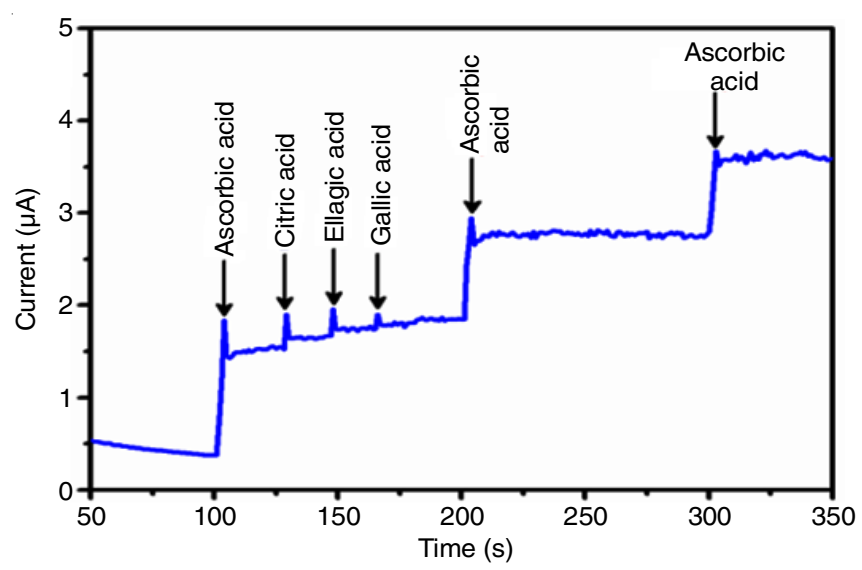

Fig. 7. Amperometric response of the GQDs/CPE modified electrode of ascorbic acid in the presence of some interfering species

method involving oxidation of ascorbic acid at the surface of a modified CPE incorporating GQDs was conducted mainly due to edge plane interaction, quantum confinement effect, large electroactive surface area and the synergistic electrocatalytic activity resulting from the combination of GQDs on CPE.

The carbene functionalized graphene quantum dots incorporated on a CPE showed a remarkable electrocatalytic activity owing to its electron deficient carbon center and interact covalently with dehydroascorbic acid. The presence of higher surface-to-volume ratio and edges provided by graphene quantum dots are responsible for the signicant higher selectivity and sensitivity towards the oxidation of ascorbic acid in a mechanistic pathway.

The electrode used for the quantification ascorbic acid is simple to use and provides rapid results towards electrochemical oxidation of ascorbic acid than unmodified CPE with a sensitivity of about $0.68 \mathrm{~mA} \mathrm{mM}^{-1}$ concentration of ascorbic acid. These experimental results indicate that the GQDs/CPE modified electrode has good prospects for the effective determination of ascorbic acid at low concentrations with high sensitivity. 


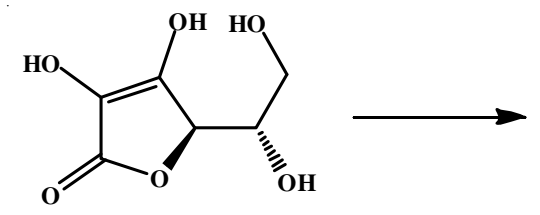

Ascorbic acid<smiles>O=C1O[C@H]([C@@H](O)CO)C(=O)C1O</smiles>

Dehydroascorbic acid

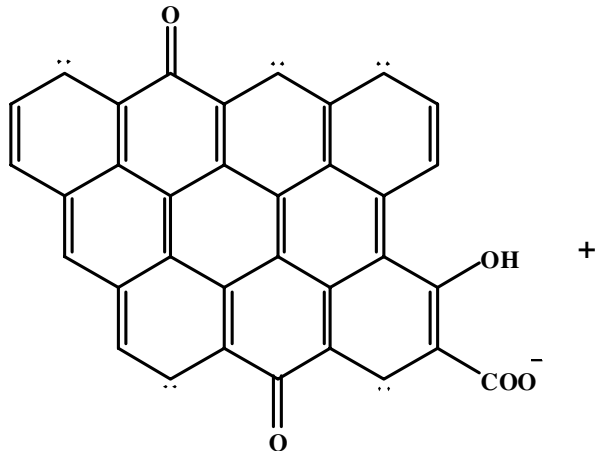

Graphene quantum dots

(I)

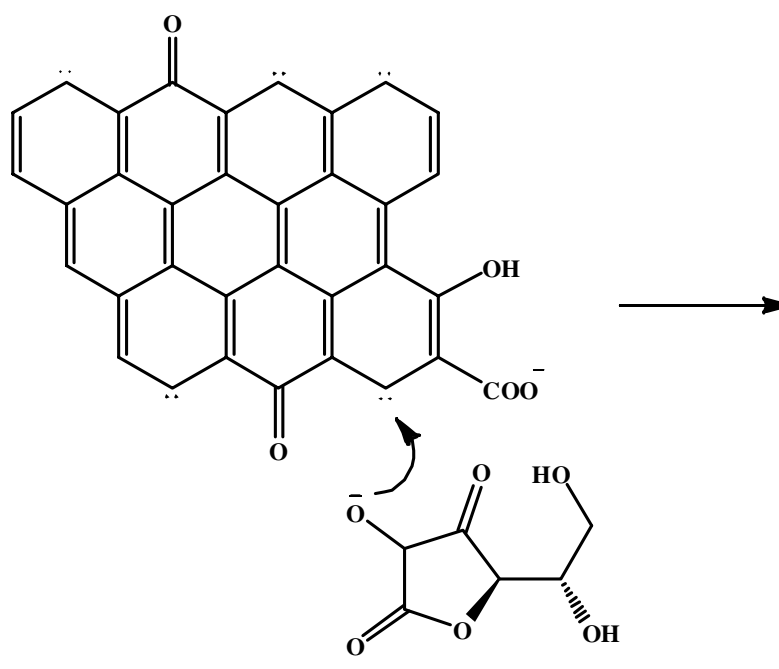

(III)

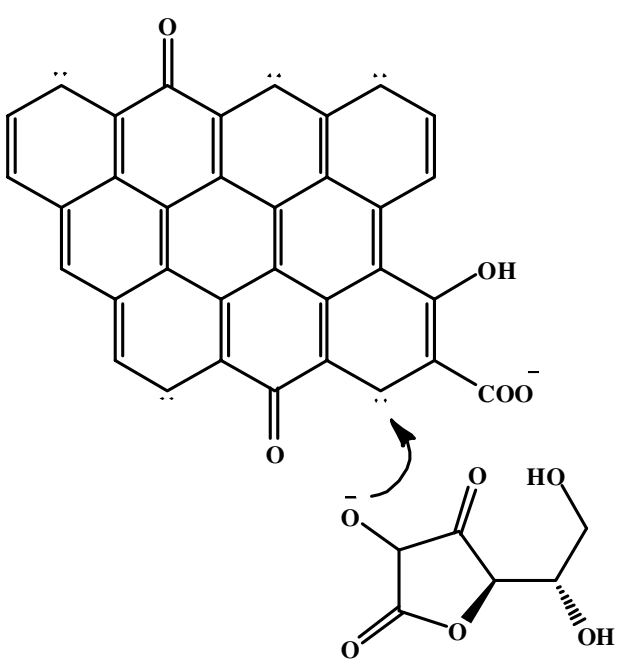

(III)

Scheme-I: Reaction mechanism pathway on electrode surface

\section{ACKNOWLEDGEMENTS}

This research was financially supported by DST-Inspire (IF120026), New Delhi, India. The authors gratefully appreciate the NCNSNT, University of Madras, Chennai, India for extending the characterization facilities.

\section{CONFLICT OF INTEREST}

The authors declare that there is no conflict of interests regarding the publication of this article.

\section{REFERENCES}

1. K.S. Novoselov, Science, 306, 666 (2004); https://doi.org/10.1126/science.1102896.

2. R.K. Gupta, Z.A. Alahmed and F. Yakuphanoglu, Mater. Lett., 112, 75 (2013);

https://doi.org/10.1016/j.matlet.2013.09.011.
3. A.A. Ensaû, M. Jafari-Asl and B. Rezaei, J. Electroanal. Chem., 731 , 20 (2014); https://doi.org/10.1016/i.jelechem.2014.07.037.

4. B.N. Patil and S.A. Acharya, Adv. Mat. Lett., 5, 113 (2014); https://doi.org/10.5185/amlett.2013.fdm.16.

5. S. Stankovich, D.A. Dikin, G.H. Dommett, K.M. Kohlhaas, E.J. Zimney, E.A. Stach, R.D. Piner, S.T. Nguyen and R.S. Ruoff, Nature, 442, 282 (2006);

https://doi.org/10.1038/nature04969.

6. S. Stankovich, D.A. Dikin, R.D. Piner, K.A. Kohlhaas, A. Kleinhammes, Y. Jia, Y. Wu, S.T. Nguyen and R.S. Ruoff, Carbon, 45, 1558 (2007); https://doi.org/10.1016/j.carbon.2007.02.034.

7. R.L. McCreery, Chem. Rev., 108, 2646 (2008); https://doi.org/10.1021/cr068076m.

8. E.P. Randviir, D.A.C. Brownson, M. Gómez-Mingot, D.K. Kampouris, J. Iniesta and C.E. Banks, Nanoscale, 4, 6470 (2012); https://doi.org/10.1039/c2nr31823g.

9. L. Li, G. Wu, G. Yang, J. Peng, J. Zhao and J.-J. Zhu, Nanoscale, 2013, 4015 (2013);

https://doi.org/10.1039/C3NR33849E. 
10. M. Yang, S. Moriyama and M. Higuchi, J. Nanosci. Nanotechnol., 14, 2974 (2014); https://doi.org/10.1166/jnn.2014.8578.

11. S.N. Baker and G.A. Baker, Angew. Chem. Int. Ed., 49, 6726 (2010); https://doi.org/10.1002/anie.200906623.

12. D. Pan, J. Zhang, Z. Li and M. Wu, Adv. Mater, 22, 734 (2010); https://doi.org/10.1002/adma.200902825.

13. F. Sekli-Belaidi, P. Temple-Boyer and P. Gros, J. Electroanal. Chem., 647, 159 (2010); https://doi.org/10.1016/j.jelechem.2010.06.007.

14. D. Manoj, D. Satheesh and J. Santhanalakshmi, Trans. Indian Inst. Metals, 64, 195 (2011); https://doi.org/10.1007/s12666-011-0038-0.

15. D.W. Hatchett and M. Josowicz, Chem. Rev., 108, 746 (2008); https://doi.org/10.1021/cr068112h.

16. Y. Xu, H. Bai, G. Lu, C. Li and G. Shi, J. Am. Chem. Soc., 130, 5856 (2008); https://doi.org/10.1021/ja800745y.

17. D. Pan, S. Wang, B. Zhao, M. Wu, H. Zhang, Y. Wang and Z. Jiao, Chem. Mater, 21, 3136 (2009); https://doi.org/10.1021/cm900395k.
18. J. Shen, Y. Zhu, X. Yang, J. Zong, J. Zhang and C. Li, New J. Chem., 36, 97 (2012); https://doi.org/10.1039/C1NJ20658C.

19. S.M. Ghoreishi, M. Behpour, M. Khayatkashani and M.H. Motaghedifard, Anal. Methods, 3, 636 (2011); https://doi.org/10.1039/c0ay00691b.

20. A.C. Ferrari, J.C. Meyer, V. Scardaci, C. Casiraghi, M. Lazzeri, F. Mauri, S. Piscanec, D. Jiang, K.S. Novoselov, S. Roth and A.K. Geim, Phys. Rev. Lett., 97, 187401 (2006); https://doi.org/10.1103/PhysRevLett.97.187401.

21. A.C. Ferrari and J. Robertson, Phys. Rev. B, 61, 14095 (2000); https://doi.org/10.1103/PhysRevB.61.14095.

22. J.I. Paredes, S. Villar-Rodil, P. Solís-Fernández, A. Martínez-Alonso and J.M.D. Tascón, Langmuir, 25, 5957 (2009); https://doi.org/10.1021/la804216z.

23. D. Satheesh, S. Shanmugam and K. Ravichandran, Mater. Lett., 137, 153 (2014); https://doi.org/10.1016/j.matlet.2014.08.147.

24. S. Kaveri and J. Ramasamy, Mater. Lett., 113, 5 (2006); https://doi.org/10.1016/j.matlet.2013.09.044. 